•研究报告・

\title{
美塘、可可西里无人区野牦牛种群数量和分布现状
}

\author{
胡一鸣 $1,2,3 \#$ 李玮琪 $2,3 \#$ 蒋志刚 ${ }^{2,3}$ 刘务林 ${ }^{4}$ 梁健超 ${ }^{1}$ \\ 林宜舟 ${ }^{5}$ 黄志文 ${ }^{1}$ 覃海华 ${ }^{1}$ 金 崑 ${ }^{6 *}$ 胡慧建 $^{1^{*}}$ \\ 1 (广东省生物资源应用研究所, 广东省动物保护与资源利用重点实验室, \\ 广东省野生动物保护与利用公共实验室, 广州 510260) \\ 2 (中国科学院动物研究所, 北京 100101) \\ 3 (中国科学院大学, 北京 100049) \\ 4 (西藏自治区林业调查规划研究院, 拉萨 850000) \\ 5 (广州翼林生态监测有限公司, 广州 510075) \\ 6 (中国林业科学研究院森林生态环境与保护研究所, 北京 100091)
}

\begin{abstract}
摘要: 野牦牛(Bos grunniens)是青藏高原特有的大型有蹄类动物, 主要分布在西藏差塘, 青海可可西里、三江源, 新疆阿尔金山等地的高海拔生境。我们于2012-2014年在西藏美塘和青海可可西里对野牦牛进行了较为全面的实 地调查, 并且估算西藏芫塘地区野牦牛种群在 $11,222-21,072$ 头之间, 可可西里野牦牛种群数量在659-1,793头之 间。据本次野外调查和历史文献资料显示, 自 20 世纪 90 年代起, 中国野牦牛种群数量逐年增长, 但是其分布区面积 却逐步缩减, 目前仅分布在几个相对孤立且远离人类居住地的高寒区域。随着全球气候变化与青藏高原人类活动 的加强, 野牦牛的生存现状依然严峻, 我们仍需加强对青藏高原特有物种的保护。
\end{abstract}

关键词: Bos grunniens; 青藏高原; 种群数量; 分布; 保护

\section{A wild yak survey in Chang Tang of Tibet Autonomous Region and Hoh Xil of Qinghai Province}

\author{
Yiming $\mathrm{Hu}^{1,2,3 \#}$, Weiqi $\mathrm{Li}^{2,3 \#}$, Zhigang Jiang ${ }^{2,3}$, Wulin $\mathrm{Liu}^{4}$, Jianchao Liang ${ }^{1}$, Yizhou Lin ${ }^{5}$, Zhiwen Huang ${ }^{1}$, \\ Haihua Qin ${ }^{1}$, Kun $\operatorname{Jin}^{6 *}$, Huijian $\mathrm{Hu}^{1 *}$ \\ 1 Guangdong Key Laboratory of Animal Conservation and Resource Utilization, Guangdong Public Laboratory of Wild \\ Animal Conservation and Utilization, Guangdong Institute of Applied Biological Resources, Guangzhou 510260 \\ 2 Institute of Zoology, Chinese Academy of Sciences, Beijing 100101 \\ 3 University of Chinese Academy of Sciences, Beijing 100049 \\ 4 Forestry Inventory and Planning Institute of the Tibet Autonomous Region, Lhasa 850000 \\ 5 Guangzhou Yilin Ecological Monitoring Limited Company, Guangzhou 510075 \\ 6 Research Institute of Forest Ecology Environment and Protection, Chinese Academy of Forestry, Beijing 100091
}

\begin{abstract}
The wild yak (Bos grunniens), which is endemic to the Qinghai-Tibet Plateau, mainly distributed in Chang Tang region of Tibet, Hoh Xil and Sanjiangyuan regions of Qinghai and Altun Mountain of Xinjiang. In this study, we used field data and data from the published literatures to estimate the population of wild yaks as well as their distribution in the Qinghai-Tibet Plateau and the adjacent areas in China. Field surveys were conducted in Chang Tang of Tibet, Hoh Xil of Qinghai between 2012 and 2014. According to our field survey, there were 11,222-21,072 wild yaks in Chang Tang of Tibet, and 659-1,793 in Hoh Xil of Qinghai. Although our results indicate that the population of wild yak has increased since 1990s, the distribution area of wild yak is shrinking. With the changing of the global climate and the intensifying of human activities on the Qinghai-Tibet Plateau, stronger actions to protect the endemic species in this area are still needed.
\end{abstract}

Key words: Bos grunniens; Qinghai-Tibet Plateau; population; distribution; conservation

收稿日期: 2017-12-09; 接受日期: 2018-02-20

基金项目: 国家自然科学基金(31400361)、科技基础性专项(2013FY110300)、环境保护部生物多样性专项、广东省省级科技计划项目(2013B061800042)

\# 共同第一作者 Co-first authors

* 共同通讯作者 Co-author for correspondence. E-mail: jk2002@caf.ac.cn; 13922339577@139.com 
野牦牛(Bos grunniens)是青藏高原特有物种, 为典型的高寒区动物(Wiener et al, 2003)。20世纪中 至 21 世纪初, 其数量不断下降, 一度面临灭绝的风 险(Schaller, 1998; 姚军等, 2006)。目前, 野牦牛被 IUCN红色名录列为易危(VU), 同时也是我国国家 一级保护动物(蒋志刚等, 2015)。作为青藏高原的旗 舰物种, 野牦牛是我国现存体型最大的有蹄类动物, 体长200-280 cm, 肩高160-180 cm, 体重在500 kg 以上, 是重要的野生动物资源(Smith和解炎, 2009)。

野牦牛分布在青藏高原以及周围邻近地区海 拔 3,200-6,100 $\mathrm{m}$ 的高寒生境 (Buzzard \& Berger, 2016), 主要集中在西藏的㒸塘, 青海的可可西里、 三江源，新疆的阿尔金山等地区(路飞英等, 2015; Shi et al, 2016; Liang et al, 2016), 甘肃和四川历史 上也有分布记录(Shi et al, 2016)。

严酷的自然环境制约了对野牦牛的研究和监 测。新中国成立前仅有一些探险队和旅行家在西藏 对哺乳动物作过零星的采集和记述。解放后, 我国 对西藏野生动物资源进行了多次调查：1959年5-8 月, 中国珠穆朗玛峰登山队科学考察队动物组首次 对珠峰地区进行了考察; 1966年5-7月, 中国科学院 组织了西藏科学考察队, 完成了波曲河谷和希夏邦 马峰北部色龙的调查，1967年9月又在吉隆进行植 物和动物调查; 1973-1977年, 中国科学院青藏高原 综合科考队开展考察(中国科学院青藏高原综合科 学考察队, 1986)。但是专门针对野牦牛的野外科考 直到1984年才真正开始(刘务林和Schaller，2003), 相关研究主要集中在种群分布、数量、栖息地和遗 传进化等领域(Harris et al, 1999; 刘务林和Schaller, 2003; Berger et al, 2015)。20世纪90年代以来, 关于 野牦牛的调查研究不断增多, 但大部分的研究仅在 新疆、青海和西藏的局部地区开展(Leslie \& Schaller, 2009)。其中新疆的野牦牛种群研究开始较早且较为 详尽。20世纪 80 年代在阿尔金山自然保护区的研究 表明, 该地区的野牦牛数量约为 10,000 头; 但是因 为非法狩猎活动较多, 90年代初大幅下降, 学者们 估计整个新疆的数量下降至 1,700-2,500头之间 (Schaller \& Liu, 1996; Schaller, 1998; Buzzard et al, 2010)。青海野牦牛种群的系统研究开始较晚, 朴仁 珠等(1999)在可可西里自然保护区进行了野外调查, 并估算该地区约有 11,000 头; 刘务林和 Schaller (2003)认为在青海布尔汗布达山的野牛沟里(面积
$1,051 \mathrm{~km}^{2}$ )大约分布有 1,000 头。西藏芫塘地区较为 完善的野牦牛种群研究直到 21 世纪初才完成, 推算 㒸塘保护区的野牦牛数量为 $7,000-7,500$ 头(刘务林 和Schaller, 2003)。

对野生动物种群数量和分布状况的调查和监 测是对动物资源和野生动物栖息地进行有效管理 的基础。在全球气候变暖和青藏高寒区内人为活动 不断加剧的情况下, 我国野牦牛的种群数量和分布 区等信息有待更新。我们于2012-2014年间多次在 西藏㒸塘和青海可可西里开展调查, 并估算出野牦 牛的种群数量, 以探讨其分布现状。

\section{1 研究区概况和研究方法}

\section{1 调查区域概况}

青藏高原是世界上面积最大、海拔最高的高原 $\left(28^{\circ} 32^{\prime}-40^{\circ} 01^{\prime} \mathrm{N}, 78^{\circ} 27^{\prime}-104^{\circ} 43^{\prime} \mathrm{E}\right)$, 平均海拔高达 $4,500 \mathrm{~m}$, 占中国国土面积 $25 \%$ 以上(张荣祖, 2011), 其中 $85 \%$ 以上的地区海拔超过 $3,000 \mathrm{~m}$ 。该区地形地 貌复杂, 区内有高山、峡谷、水系、湖泊、盆地、 冰川与冻土等多种地貌类型(刘军会等, 2013)。青藏 高原中部属于亚寒带气候, 西部为半干旱气候, 北 部属于寒带干旱气候; 大部分地区年平均气温在 $0{ }^{\circ} \mathrm{C}$ 以下, 冬季最低气温低于 $-40^{\circ} \mathrm{C}$ (张荣祖, 2011)。 青藏高原的降水主要集中在7-9月, 高海拔地区通 常是固态降水; 大部分地区因受内陆高压控制, 年 平均降水量小于 $400 \mathrm{~mm}$, 仅青藏高原东南缘地区 因受到西南季风的影响年均降水量大于 $400 \mathrm{~mm}$ (刘 军会等, 2013)。青藏高原独特的地形地貌以及气候 造就了其独特的植被类型: 由东南向西北呈森林、 草甸、草原、荒漠更替; 其中高寒草地分布最广, 可 细分为高山草甸、高山干旱草原和荒漠草原3种类 型(王香亭, 1991)。区内动物群以古北界区系成分为 主, 高原特有物种丰富, 有野牦牛、藏羚(Pantholops hodgsonii)、藏原羚(Procapra picticaudata)、普氏原 羚(P. przewalskii)、西藏盘羊(Ovis hodgsoni)、藏野 驴(Equus kiang)、棕熊(Ursus arctos)、荒漠猫(Felis bieti)、赤狐(Vulpes vulpes)、狼(Canis lupus)和黑颈 鹤(Grus nigricollis)等。

\section{2 样线布设与调查的实施}

本次调查的重点区域是㒸塘的阿里和那曲地 区，青海可可西里地区。根据中国科学院计算机网 络信息中心国际科学数据镜像网站(http://www.gs 
cloud.cn/) $90 \mathrm{~m}$ 精度的数字高程数据, 利用ArcGIS 10.2软件(ESRI, Redlands, CA, USA)根据历史研究 的野牦牛分布数据绘制其分布图(覆盖除仲巴和昂 仁措勤以外的其余青藏高原野牦牛历史分布区), 并把调查区划分为 $30 \mathrm{~km} \times 30 \mathrm{~km}$ 的调查单元。在区 内随机选择一个单元按照确定的间隔(间隔为上下 左右每隔 2 个样区抽取 1 个), 系统地抽取相应的单 元组成调查样区。在抽取的 $30 \mathrm{~km} \times 30 \mathrm{~km}$ 样区内布 设样线(单侧带宽 $5,000 \mathrm{~m}$ )。共布设样线 69 条, 其中 阿里地区 28 条, 那曲地区 31 条, 可可西里地区 10 条。因受地形的可通行性限制, 调查时的实际样线 与理论样线存在差异(样线具体布设情况见附录1)。

分别于 2012年12月、2013年6月和2014年5月在 芫塘的阿里地区进行调查; 于2012年12月、2013年6 月和2014年12月在㒸塘那曲地区进行调查; 于 2014 年8月和 12 月在可可西里样区进行调查。乘车开展 调查, 车辆沿着固定的路线以 $10-20 \mathrm{~km} / \mathrm{h}$ 的速度行 驶, 发现野牦牛时停车通过双筒望远镜或高倍单筒 望远镜观察, 记录样线内出现的野牦牛群和个体数 量, 如能辨别性别、亚成体和幼体则进行相应的记 录, 并用GPS记录其活动位点的栖息地类型。在调 查中遇到疑似家养的牦牛个体, 我们首先从体型与 表型特征判断个体是否野牦牛; 如果野牦牛的特征 不明显, 我们则通过动物的行为来判断其是否野生 牦牛, 若判定其为家牦牛, 将不对其进行统计。为 避免重复计数, 每个 $30 \mathrm{~km} \times 30 \mathrm{~km}$ 样区的调查均在 同一天之内完成(Schaller et al, 1991)。

\section{3 野外调查的种群数量估算}

利用方差分析法(Thomas et al, 2009)来估算调 查区域内的野牦牛种群密度:

每条样线的种群密度 $D_{i}=\frac{N_{i}}{\mathrm{~S}_{i}}$

平均种群密度 $\bar{D}=\frac{1}{m} \sum D_{m}$

标准差 $S F=\sqrt{\frac{\sum\left(\bar{D}-D_{m}\right)^{2}}{m-1}}$

种群密度范围 $D_{q}=\bar{D} \pm \Delta$

种群数量 $N_{q}=D_{q} \times S=(\bar{D} \pm \Delta) \times S$

$N_{i}$ 是样线 $i$ 上记录的有效物种数量, $S_{i}$ 是样线面积, $S_{i}$ =样线 $i$ 的长度 $\times$ 样线 $i$ 的宽度 $(5,000 \mathrm{~m})$ 。 $m$ 是研究
区域所有的样线数量, $\Delta$ 为抽样误差, $\Delta=\frac{\mathrm{t}_{\alpha} \times S F}{\sqrt{m-1}}$; $\mathrm{t}_{\alpha}$ 为置信度, $\mathrm{t}_{\alpha}=95 \%, S$ 是野牦牛的栖息地面积。

\section{2 结果}

\section{1 种群数量}

本次野外调查共完成样线 $5,109.56 \mathrm{~km}$, 其中阿 里地区2,607.5 km, 那曲地区1,783.69 km, 可可西 里自然保护区718.37 km, 样线面积为 $25,547.8 \mathrm{~km}^{2}$ 。 野外调查共记录到野牦牛个体 1,437 头, 密度为 0.056 头 $/ \mathrm{km}^{2}$ 。其中西藏㒸塘阿里地区 255 头, 密度为 0.014 头 $/ \mathrm{km}^{2}$, 那曲地区 1,083 头, 密度为 0.136 头 $/ \mathrm{km}^{2}$; 青海可可西里地区 99 头, 密度为 0.027 头 $/ \mathrm{km}^{2}$ (表1)。本次调查记录到的野牦牛群体以 10 头以 下的小群体为主, 占总记录数的 $88.55 \% ; 20$ 头以上 的群体较少, 仅观测到 10 群, 占总群体数的 $4.41 \%$; 其中最大一个群体的个体数为 51 头。根据公式 (1)-(5), 西藏㒸塘地区野牦牛种群在11,222-21,072 头之间, 青海可可西里野牦牛种群数量在659-1,793 头之间。

\section{2 野牦牛群体性别与年龄组成}

本次调查能够区分性比的记录仅有 60 个小群 (附录1)。这些样本平均 2.3 头/群, 成年雌、成年雄 和亚成体(包括幼葸)的比例为 $105: 24: 9$ 。成年野牦牛 雌雄不同群。雄性单个成群的情况最常见, 共42例, 占到样本群体的 $70 \%$; 也有数头雄性组成一群的情 况, 其中 2 头群 10 例, 占 $16.7 \%, 3$ 头群 3 例，占 $15 \%, 4$ 头群 2 例, 占 $13.3 \%, 13$ 头群 2 例, 占 $13.3 \%$ 。成年雌性 和亚成体组成的群 1 例, 占 $1.7 \%$ 。

\section{3 野牦牛栖息地特点}

本次调查发现野牦牛垂直分布范围从海拔 4,300-5,525 m, 平均海拔为 $5,125 \mathrm{~m}$ 。野牦牛发现点 的地形多为陡峭的山地, 其中群体数量较大的群多 出现在山体间的沟谷中。这些沟谷隐蔽性好(一般要 驱车至山顶才能观察到沟谷中的具体情况), 水源 充足, 植被较丰富。总体而言野牦牛的栖息地多在 植被丰富的雪山或临近水源(冰川、湖泊等)的高大 山体附近。其中, 高寒草地(特别是高山草甸)是野牦 牛适宜的栖息地, 也是野牦牛密度最高的地区(如 本次野外调查的那曲地区, 野牦牛密度高达 0.136 头 $/ \mathrm{km}^{2}$ )。 
表1 中国野牦牛分布区域、分布密度及种群数量一一调查数据

Table 1 Distribution, density and population size of wild yaks in China: field data

\begin{tabular}{llllll}
\hline 省份 Province & 分布区 Distribution & 经纬度 Latitude \& longitude & \multicolumn{1}{l}{ 面积 Area $\left(\mathrm{km}^{2}\right)$} & 密度 Density (inds./km²) 种群数量 Population size \\
\hline 西藏 Tibet & 阿里 Ngari & $32^{\circ} 10^{\prime}-36^{\circ} 32^{\prime} \mathrm{N}, 79^{\circ} 42^{\prime}-92^{\circ} 05^{\prime} \mathrm{E}$ & 134,000 & $0.014 \pm 0.005$ & $1,859 \pm 713$ \\
& 那曲 Nagchu & & 105,000 & $0.136 \pm 0.040$ & $14,288 \pm 4,212$ \\
& & & & \\
青海 Qinghai & 可可西里 Hoh Xil & $34.19^{\circ}-36.16^{\circ} \mathrm{N}, 89.25^{\circ}-94.05^{\circ} \mathrm{E}$ & 45,000 & $0.027 \pm 0.0126$ & $1,226 \pm 567$ \\
\hline
\end{tabular}

阿里和那曲地区面积数据为实际调查区域面积减去该区水体面积; 可可西里面积数据来自中华人民共和国环境保护部(http://www.mep.gov.cn/stbh/)。

\section{3 讨论}

\section{1 我国野牦牛种群数量现状}

从20世纪 90 年代开始, 我国野牦牛种群数量稳 步上升。研究表明, 1984-1994年我国野牦牛种群数 量在13,200-14,700头之间, 其中西藏有8,000-8,500 头，青海有3,200-3,700头，新疆有 2,000-2,500头 (Schaller \& Liu, 1996; 刘务林和Schaller, 2003); 朴 仁珠等(1999)估计我国野牦牛数量在15,212-20,000 头之间; 姚军等(2006)估计我国野牦牛数量在 15,788-23,692头之间; 张知贵等(2009)估计我国野 牦牛数量在 $24,000-30,000$ 头之间。

近年来，我国有效遏制了对野牦牛的非法捕猎 活动, 野牦牛种群数量稳步增长。野牦牛分布区域 广阔, 在人力物力有限的情况下, 目前基于野外调 查估算的野牦牛数量可能存在偏差。为了准确地掌 握我国野牦牛种群数量状况, 必须在所有野牦牛分 布区内进行统一方法的同步调查。特别是一些被忽 略的野牦牛潜在栖息地, 如四川和甘肃的野牦牛历 史分布区，亟需开展野外调查工作。

本次野外调查未能覆盖的野牦牛分布区的种
群状况如下：西藏昂仁措勤地区的野牦牛数量在 954-1,434头之间，青海三江源自然保护区和祁连 山一疏勒南山地区约有野牦牛 2,479 头，新疆阿尔金 山自然保护区的野牦牛数量在 $10,623-19,077$ 头之 间，甘肃肃南、肃北地区有记录到野牦牛130头(表 2)。综上，西藏野牦牛的种群在12,106-22,436头之 间, 青海野牦牛种群约有 3,138-4,272头, 新疆野牦 牛种群约为 $10,623-19,077$ 头, 甘肃估计有 130 头(路 飞英等, 2015; Shi et al, 2016), 全国野牦牛数在 $27,220-47,138$ 头之间。

\section{2 野牦牛种群结构}

目前在缺乏野牦牛种群性比、种群年龄结构信 息的情况下，仅通过粗略估算得出的种群数量难以 反映野生动物种群的实际情况。种群中的幼崽数量 比例是种群发展的标志，刘务林和Schaller (2003) 曾指出我国野牦牛种群的幼崽比例偏低: 正常的野 牦牛种群中大约有 $10-15 \%$ 是由幼崽组成的，但根 据 20 世纪 90 年代初在羌塘北部地区连续数年的观 察而统计得到的野牦牛幼崽数量仅为 $5 \%$ 甚至更少。 某区域种群幼崽数量连年过低意味着该种群存在 不断缩减的风险。本研究野外调查发现，成年野牛

表2 中国野牦牛分布区域、分布密度及种群数量—文献数据

Table 2 Distribution, density and population size of wild yaks in China: literature data

\begin{tabular}{|c|c|c|c|c|c|c|}
\hline $\begin{array}{l}\text { 省份 } \\
\text { Province }\end{array}$ & $\begin{array}{l}\text { 分布区 } \\
\text { Distribution }\end{array}$ & $\begin{array}{l}\text { 经纬度 } \\
\text { Locality }\end{array}$ & $\begin{array}{l}\text { 面积 } \\
\text { Area }\left(\mathrm{km}^{2}\right)\end{array}$ & $\begin{array}{l}\text { 密度 Density } \\
\text { (inds. } / \mathrm{km}^{2} \text { ) }\end{array}$ & $\begin{array}{l}\text { 种群数量 } \\
\text { Population size }\end{array}$ & $\begin{array}{l}\text { 数据来源 } \\
\text { Sources }\end{array}$ \\
\hline \multirow[t]{2}{*}{ 西藏 Tibet } & 仲巴 Zhongba & $\begin{array}{l}29^{\circ} 09^{\prime}-31^{\circ} 48^{\prime} \mathrm{N} \\
82^{\circ} 00^{\prime}-84^{\circ} 45^{\prime} \mathrm{E}\end{array}$ & 12,368 & 0.065 & $810 \pm 160$ & Shi et al, 2016 \\
\hline & 昂仁措勤 Angrencuoqin & $\begin{array}{l}29^{\circ} 10^{\prime}-31^{\circ} 00^{\prime} \mathrm{N} \\
85^{\circ} 09^{\prime}-87^{\circ} 45^{\prime} \mathrm{E}\end{array}$ & 15,617 & 0.021 & $314 \pm 80$ & Shi et al, 2016 \\
\hline \multirow[t]{2}{*}{ 青海 Qinghai } & $\begin{array}{l}\text { 三江源 } \\
\text { The Three River Source region }\end{array}$ & $\begin{array}{l}31^{\circ} 39^{\prime}-36^{\circ} 12^{\prime} \mathrm{N} \\
89^{\circ} 45^{\prime}-102^{\circ} 2^{\prime} \mathrm{E}\end{array}$ & 65,000 & 0.032 & 2,087 & Shi et al, 2016 \\
\hline & $\begin{array}{l}\text { 祁连山-疏勒南山 } \\
\text { Qilian Mountain-Shulenan } \\
\text { Mountain }\end{array}$ & $38^{\circ} 28^{\prime} \mathrm{N}, 97^{\circ} 45^{\prime} \mathrm{E}$ & 45,000 & 0.009 & 392 & Shi et al, 2016 \\
\hline 新疆 Xinjiang & $\begin{array}{l}\text { 阿尔金山 } \\
\text { Altun Mountains }\end{array}$ & $\begin{array}{l}36^{\circ} 00^{\prime}-37^{\circ} 49^{\prime} \mathrm{N} \\
87^{\circ} 10^{\prime}-91^{\circ} 18^{\prime} \mathrm{E}\end{array}$ & 45,000 & $0.33 \pm 0.094$ & $14,850 \pm 4,227$ & 路飞英等, 2015 \\
\hline 甘肃 Gansu & $\begin{array}{l}\text { 祁连山-肃南, 肃北 } \\
\text { Qilian Mountain-northern and } \\
\text { southern Gansu }\end{array}$ & $\begin{array}{l}32^{\circ} 11^{\prime}-42^{\circ} 57^{\prime} \mathrm{N} \\
92^{\circ} 13^{\prime}-108^{\circ} 46^{\prime} \mathrm{E}\end{array}$ & 454,430 & & 130 & Shi et al, 2016 \\
\hline
\end{tabular}




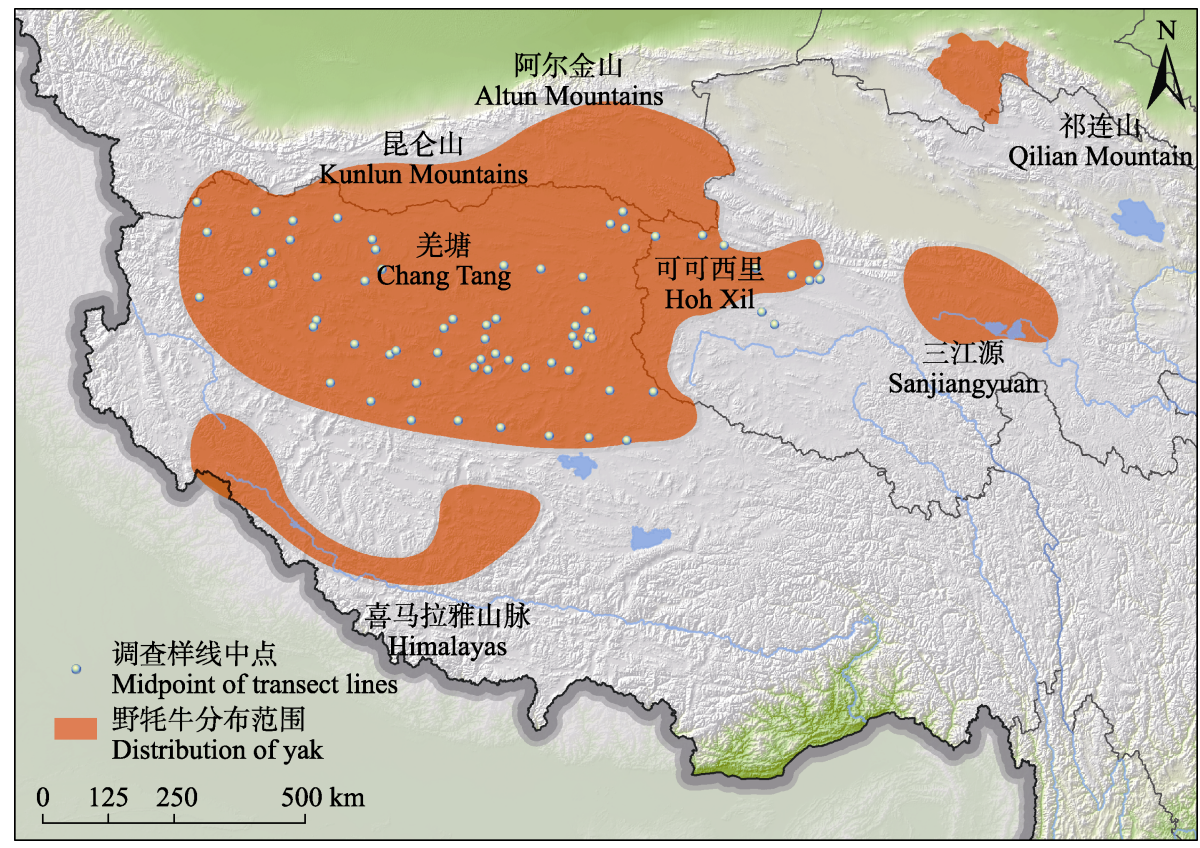

图1 中国野牦牛分布范围示意图

Fig. 1 Distribution of wild yaks in China

牛雌雄不同群, 这与冬季野牦牛处于非繁殖期有很 大关系。而雌性集大群应该和护犊有关, 群体越大 越利于保护幼体免于捕食者的侵袭。本研究的野外 调查并没有收集到足够的野牦牛种群年龄结构信 息, 无法准确评估野牦牛种群的繁育情况。

\section{3 野牦牛分布区概况}

野牦牛在西藏、青海、新疆、甘肃四省的分布 区总面积约 $921,415 \mathrm{~km}^{2}$ (图1), 主要分布在西藏、青 海、新疆三省，其中㒸塘自然保护区、可可西里自 然保护区、三江源自然保护区和阿尔金山自然保护 区的数量超过全国总数的 $95 \%$ 。

在近一个世纪以来, 随着全球气候变化与人类 活动的加强, 我国野牦牛目前仅分布在远离人类居 住地的高寒地区(姚军等, 2006; Luo et al, 2012; Liang et al, 2016; Buzzard \& Berger, 2016), 且分布区 已被分隔为几个相对孤立的区域(图1)。

\section{4 小结}

我国政府为了更好地保护野牦牛等高原野生 动物及其栖息地, 先后在新疆阿尔金山、西藏㒸塘、 可可西里和青海三江源等地区建立了国家级自然 保护区, 加上社会各界对野生动物的关注和保护; 我国野牦牛种群数量有所增长, 但是目前我国野牦 牛种群依然面临着多方面的威胁, 如栖息地破坏、
偷猎与捕杀和遗传与疾病 (Schaller \& Liu，1996; Buzzard \& Berger, 2016)。随着全球气候变化与青藏 高原人类活动的加强, 野牦牛的保护现状依然严峻, 我们必须对野牦牛分布区内的适宜栖息地加强保 护, 开展对野牦牛种群的监测, 及时获取最新的种 群及其分布区状况，以制定更为完善的保护策略。

致谢：感谢西藏林业厅、西藏差塘国家级自然保护 区、西藏珠穆朗玛峰国家级自然保护区与可可西里 国家级自然保护区对野外工作给予大力的支持; 感 谢 WCS 中国项目; 感谢野外科考队伍的所有队员; 感谢文稿修改过程中编辑部与审稿人给予的宝贵 意见。

\section{参考文献}

Berger J, Schaller GB, Cheng E, Kang A, Krebs M, Li L, Mark $H$ (2015) Legacies of past exploitation and climate affect mammalian sexes differently on the roof of the world: The case of wild yaks. Scientific Reports, 5, 8676.

Buzzard PJ, Berger J (2016) Bos mutus. The IUCN Red List of Threatened Species 2016: http://www.iucnredlist.org/details /2892/0. (accessed on 2017-09-14)

Buzzard PJ, Zhang HB, Xu DH, Wong HM (2010) A globally important wild yak Bos mutus population in the Arjinshan Nature Reserve, Xinjiang, China. Oryx, 44, 577-580. 
Harris RB, Pletscher DH, Loggers CO, Miller DJ (1999) Status and trends of Tibetan Plateau mammalian fauna, Yeniugou, China. Biological Conservation, 87, 13-19.

Jiang ZG, Ma Y, Wu Y, Wang YX, Zhou KY, Liu SY, Feng ZJ (2015) China's Mammal Diversity and Geographic Distribution. Science Press, Beijing. (in Chinese) [蒋志刚, 马勇, 吴毅, 王应祥, 周开亚, 刘少英, 冯祚建 (2015) 中国哺 乳动物多样性及地理分布. 科学出版社, 北京.]

Leslie DM, Schaller GB (2009) Bos grunniens and Bos mutus (Artiodactyla: Bovidae). Mammalian Species, 836, 1-17.

Liang X, Kang A, Nathalie P (2016) Understanding habitat selection of the vulnerable wild yak Bos mutus on the Tibetan Plateau. Oryx, 51, 361-369.

Liu JH, Gao JX, Wang WJ (2013) Variations of vegetation coverage and its relations to global climate changes on the Tibetan Plateau during 1981-2005. Journal of Mountain Science, 31, 234-242. (in Chinese with English abstract) [刘 军会, 高吉喜, 王文杰 (2013) 青藏高原植被覆盖变化及 其与气候变化的关系. 山地学报, 31, 234-242.]

Liu WL, Schaller GB (2003) Distribution and status of wild yak. Tibet Science and Technology, 11, 17-23. (in Chinese) [刘务林, Schaller GB (2003) 野牦牛的分布和现状. 西藏 科技, 11, 17-23.]

Lu FY, Shi JB, Zhang ZH, Su XK, Wu Y, Dong SK, Li XW, Zhang X, Xu DH, Gao F, Weng J (2015) Surveys of Tibetan antelope, kiang and wild yak in Arjinshan Nature Reserve, Xinjiang, China. Journal of Beijing Normal University (Natural Science), 4, 374-381. (in Chinese with English abstract) [路飞英，石建斌，张子慧，苏旭坤，吴娱，董世鬼， 李晓文, 张翔, 许东华, 高峰, 翁晋 (2015) 阿尔金山自 然保护区藏羚羊、藏野驴和野牦牛的数量与分布. 北京师 范大学学报(自然科学版), 4, 374-381.]

Luo ZH, Tang SH, Li CL, Fang HZ, Hu HJ, Yang J, Ding JJ, Jiang ZG (2012) Environmental effects on vertebrate species richness: Testing the energy, environmental stability and habitat heterogeneity hypotheses. PLoS ONE, 7, e35514.

Piao RZ, Ma YQ, Cui HS (1999) Current situation of the yak population in China. Life Science Research, 3, 161-169. (in Chinese with English abstract) [朴仁珠, 马逸清, 崔花淑 (1999) 中国野牦牛现状研究. 生命科学研究, 3, 161-169.]

Schaller GB (1998) Wildlife of the Tibetan Steppe. University of Chicago Press, Chicago.

Schaller GB, Liu W (1996) Distribution, status, and conservation of wild yak Bos grunniens. Biological Conservation, 76,
$1-8$.

Schaller GB, Ren J, Qiu M (1991) Observations on the Tibetan antelope (Pantholops hodgsoni). Applied Animal Behaviour Science, 29, 416-422.

Shi Q, Guo Y, Engelhardt SC, Weladji RB, Zhou Y, Long M, Meng X (2016) Endangered wild yak (Bos grunniens) in the Tibetan Plateau and adjacent regions: Population size, distribution, conservation perspectives and its relation to the domestic subspecies. Journal for Nature Conservation, 32, 35-43.

Smith AT, Xie Y (2009) A Guide to the Mammals of China. Hunan Education Press, Changsha. (in Chinese) [Smith AT, 解炎 (2009) 中国兽类野外手册. 湖南教育出版社, 长 沙.]

The Comprehensive Scientific Expedition to the Qinghai-Xizang Plateau, Chinese Academy of Science (1986) The Mammals of Xizang. Science Press, Beijing. (in Chinese) [中国科学院青藏高原综合科学考察队 (1986) 西藏 哺乳类. 科学出版社, 北京.]

Thomas L, Buckland S, Burnham K, Anderson D, Laake J, Borchers D, Strindberg S (2002) Distance sampling. Encyclopedia of Environmetrics, 1, 544-552.

Wang XT (1991) Vertebrate Fauna of Gansu. Gansu Science and Technology Press, Lanzhou. (in Chinese) [王香亭 (1991) 甘肃脊椎动物志. 甘肃科学技术出版社, 兰州.]

Wiener G, Han J, Long R (2003) The Yak. 2nd edn. Regional Office for Asia and the Pacific of the Food and Agriculture Organization of the United Nations, Bangkok.

Yao J, Yang BH, Yan P, Liang CN, Guo J, Jiao S, Lang X, Guo X, Feng RL, Cheng SL (2006) Analysis on habitat variance and behaviour of Bos gruiens in China. Acta Prataculturae Sinica, 15, 124-128. (in Chinese with English abstract) [姚 军, 杨博辉, 问萍, 梁春年, 郭健, 焦硕, 郎侠, 郭宪, 冯 瑞林, 程胜利 (2006) 中国野牦牛栖息地环境及种群行 为分析. 草业学报, 15, 124-128.]

Zhang RZ (2011) Zoogeography of China. Science Press, Beijing. (in Chinese) [张荣祖 (2011) 中国动物地理. 科学出 版社, 北京.]

Zhang ZG, Xia L, Yang QS (2009) Distribution and conservation of yak (Bos grunniens). Chinese Journal of Zoology, 44(1), 148-150. (in Chinese with English abstract) [张知贵, 夏霖, 杨奇森 (2009) 牦牛的分布及保护. 动物学杂志, 44(1), 148-150.]

(责任编委: 李俊生 责任编辑: 时意专)

\section{附录 Supplementary Material}

附录 1 野外调查部分野牦牛群体性别组成情况

Appendix 1 Gender composition of wild yaks http://www.biodiversity-science.net/fileup/PDF/2017340-1.pdf 
胡一鸣, 李玮琪, 蒋志刚, 刘务林, 梁健超, 林宜舟, 黄志文, 覃海华, 金崑, 胡慧建. 生物多样性, 2018, 26(2): 185-190. 西藏芫塘和青海可 可西里无人区野牦牛种群数量和分布现状.

http://www.biodiversity-science.net/CN/10.17520/biods.2017340

附录1 野外调查部分野牛牛群体性别组成情况

Appendix 1 Gender composition of wild yaks.

\begin{tabular}{|c|c|c|c|c|c|c|c|c|c|c|c|c|c|c|}
\hline 群号 & 总数 & 雌 & 雄 & 亚成体 & 群号 & 总数 & 雌 & 雄 & 亚成体 & 群号 & 总数 & 雌 & 雄 & 亚成体 \\
\hline 1 & 33 & 24 & 0 & 9 & 21 & 1 & 0 & 1 & 0 & 41 & 1 & 0 & 1 & 0 \\
\hline 2 & 2 & 0 & 2 & 0 & 22 & 1 & 0 & 1 & 0 & 42 & 1 & 0 & 1 & 0 \\
\hline 3 & 1 & 0 & 1 & 0 & 23 & 2 & 0 & 2 & 0 & 43 & 1 & 0 & 1 & 0 \\
\hline 4 & 1 & 0 & 1 & 0 & 24 & 1 & 0 & 1 & 0 & 44 & 1 & 0 & 1 & 0 \\
\hline 5 & 1 & 0 & 1 & 0 & 25 & 1 & 0 & 1 & 0 & 45 & 1 & 0 & 1 & 0 \\
\hline 6 & 1 & 0 & 1 & 0 & 26 & 1 & 0 & 1 & 0 & 46 & 1 & 0 & 1 & 0 \\
\hline 7 & 3 & 0 & 3 & 0 & 27 & 1 & 0 & 1 & 0 & 47 & 1 & 0 & 1 & 0 \\
\hline 8 & 2 & 0 & 2 & 0 & 28 & 1 & 0 & 1 & 0 & 48 & 2 & 0 & 2 & 0 \\
\hline 9 & 1 & 0 & 1 & 0 & 29 & 1 & 0 & 1 & 0 & 49 & 1 & 0 & 1 & 0 \\
\hline 10 & 2 & 0 & 2 & 0 & 30 & 2 & 0 & 2 & 0 & 50 & 1 & 0 & 1 & 0 \\
\hline 11 & 1 & 0 & 1 & 0 & 31 & 2 & 0 & 2 & 0 & 51 & 1 & 0 & 1 & 0 \\
\hline 12 & 1 & 0 & 1 & 0 & 32 & 1 & 0 & 1 & 0 & 52 & 3 & 0 & 3 & 0 \\
\hline 13 & 1 & 0 & 1 & 0 & 33 & 13 & 0 & 13 & 0 & 53 & 4 & 0 & 4 & 0 \\
\hline 14 & 1 & 0 & 1 & 0 & 34 & 1 & 0 & 1 & 0 & 54 & 1 & 0 & 1 & 0 \\
\hline 15 & 4 & 0 & 4 & 0 & 35 & 2 & 0 & 2 & 0 & 55 & 1 & 0 & 1 & 0 \\
\hline 16 & 1 & 0 & 1 & 0 & 36 & 1 & 0 & 1 & 0 & 56 & 2 & 0 & 2 & 0 \\
\hline 17 & 1 & 0 & 1 & 0 & 37 & 2 & 0 & 2 & 0 & 57 & 13 & 0 & 13 & 0 \\
\hline 18 & 1 & 0 & 1 & 0 & 38 & 1 & 0 & 1 & 0 & 58 & 3 & 0 & 3 & 0 \\
\hline 19 & 1 & 0 & 1 & 0 & 39 & 1 & 0 & 1 & 0 & 59 & 1 & 0 & 1 & 0 \\
\hline 20 & 1 & 0 & 1 & 0 & 40 & 1 & 0 & 1 & 0 & $\mid 60$ & 1 & 0 & 1 & 0 \\
\hline
\end{tabular}

